\title{
Risk factors for respiratory assistance in premature infants
}

\author{
HAI-XIN LI ${ }^{1 *}$, CAI-JIE GAO ${ }^{2 *}$, SHAN CHENG $^{2 *}$, ZHI-LEI MAO $^{1}$ and HUAI-YAN WANG ${ }^{1}$ \\ ${ }^{1}$ Department of Child Healthcare, Changzhou Women and Children Health Care Hospital, Changzhou, Jiangsu 213000; \\ ${ }^{2}$ Department of Infectious Disease, Children's Hospital of Nanjing Medical University, Nanjing, Jiangsu 210008, P.R. China
}

Received January 23, 2020; Accepted December 10, 2020

DOI: $10.3892 /$ etm.2021.9668

\begin{abstract}
Premature infants are prone to dyspnea after birth due to immature development, and some infants require respiratory assistance. However, the risk factors for respiratory assistance in premature infants are rarely reported. The present study enrolled 3,394 premature infants (665 infants had been provided with respiratory assistance and 2,729 had not used respiratory assistance) to retrospectively analyze the risk factors associated with respiratory aid. The multivariate logistic regression analysis demonstrated that placental abnormality [odds ratio $(\mathrm{OR})=1.284 ; \mathrm{P}=0.048$ ], the male sex $(\mathrm{OR}=0.696$; $\mathrm{P}=0.001)$, delivery via cesarean section $(\mathrm{OR}=1.538$; $\mathrm{P}<0.001)$, low 1-min Apgar score $(\mathrm{OR}=0.727 ; \mathrm{P}<0.001)$, low birth weight $(\mathrm{OR}=0.999 ; \mathrm{P}=0.005)$ and low gestational age $(\mathrm{OR}=0.616 ; \mathrm{P}<0.001)$ were independent risk factors for respiratory assistance in premature infants. Overall, a number of risk factors, including placental abnormality, cesarean section, low 1-min Apgar score, low birth weight and small gestational age, were identified for respiratory assistance in premature infants. By conducting a risk assessment of risk factors at birth and using this information to provide timely respiratory assistance, the survival rates of premature infants may increase.
\end{abstract}

\section{Introduction}

The prevalence of premature delivery is on the rise worldwide, and in 2019 it was estimated that premature birth accounted for $10.6 \%$ of all live births (1). With economic development and an increase in medical knowledge, the survival rate of premature infants is increasing, reaching $>90 \%$, and the survival rate of infants with an extremely low birth weight (ELBW) with gestational age $<28$ weeks increased from 0 to $35-70 \%$ in

Correspondence to: Dr Huai-Yan Wang, Department of Child Healthcare, Changzhou Women and Children Health Care Hospital, 16 Dingxiang Road, Zhonglou District, Changzhou, Jiangsu 213000, P.R. China

E-mail: czwhy522@163.com

*Contributed equally

Key words: premature infants, respiratory assistance, risk factors high-income countries during the previous two decades (1-4). However, premature infants that survive may develop detrimental conditions, such as neurodevelopmental disabilities and bronchopulmonary dysplasia (BPD) (5).

The pulmonary cellular structure, thoracic structure and muscle strength mature in the last trimester (6), and metabolic substances that are important for effective breathing, such as pulmonary surfactant and antioxidant enzyme, are highly reserved in the last trimester (7). Therefore, pulmonary disease is a major cause of mortality in premature infants, especially in extremely premature infants (8). These infants require respiratory assistance to clear lung fluid, aerate the lungs and establish a consistent functional residual capacity to ensure gas exchange (9). Prior to the 1970 s, neonatal respiratory distress syndrome (NRDS) was the most common cause of mortality in premature infants until the emergence of assisted ventilation, which resulted in a significant increase in the survival rate of patients with the disease (10). Respiratory assistance is also an important treatment for other complications that are common in premature infants, including BPD and respiratory failure $(8,11,12)$.

Respiratory assistance includes mechanical ventilation, nasal continuous positive airway pressure (CPAP) and nasal intermittent positive pressure ventilation. A previous study has revealed that extremely preterm births require positive pressure ventilation if infants have spontaneous breathing and the use of nasal or mask CPAP is recommended (13). CPAP failure is defined as hypoxia, severe respiratory distress or apnea when $\mathrm{FiO}_{2}>0.6$ and $\mathrm{pCO}_{2}>65 \mathrm{mmHg}$ (14-16), and often requires mechanical ventilation. Due to the underdeveloped body function and organ development of premature infants who exhibit hypoimmunity, long-term respiratory assistance may also result in a number of complications. For example, an Australian study revealed that $24 \%$ of 500 pediatric patients who used respiratory assistance developed complications, including croup, epiglottitis, lung atelectasis, infection and others (17). Despite the continuous advancement of medical care, ventilator-associated pneumonia, infection and retinopathy of prematurity occur occasionally, resulting in prolonged hospital stay of newborns, of which severe cases can be life-threatening $(1,18,19)$. Therefore, investigating the risk factors of respiratory assistance in premature infants may reduce the use of ventilators and the incidence of complications via targeted pregnancy and prenatal education and can strengthen medical skills. Furthermore, using the correct personalized respiratory management in a timely manner (by 
determining whether premature infants require respiratory assistance as early as possible) will be of great significance in improving survival rates of premature infants. However, to the best of our knowledge, there are few relevant studies at present.

The current study retrospectively analyzed the factors associated with the use of ventilators in the treatment of premature infants to investigate risk factors for respiratory assistance. The results of the current study may provide evidence for the clinical early judgment of respiratory assistance contributing to an increase in survival rate of premature infants by effectively managing risk factors of respiratory assistance.

\section{Materials and methods}

Subjects. The subjects were selected from 3,578 premature infants ranging from 24 to 36 week of gestational age (mean, 33.73; SD, 2.29). They were born in Changzhou Maternal and Child Health Care Hospital (Changzhou, China) between January 1, 2013 and December 31, 2016 and were hospitalized in the neonatology department. In total, $56.48 \%$ of participants were male, $43.46 \%$ were female and $0.06 \%$ were unknown. The inclusion criteria were as follows: i) Born in Changzhou Maternal and Child Health Care hospital; ii) gestational week of delivery $<37$ weeks. The exclusion criteria were as follows: i) Patients with hospice care; ii) missing data on maternal pregnancy period or perinatal period; iii) pediatrics who were readmitted for various reasons after recovery from neonatology department; and iv) congenital abnormalities including fatal fetal anomaly, such as Edwards syndrome, anencephaly, Patau Syndrome, Renal Agenesis/Potter Syndrome, triploidy, serious open spina bifida, severe encephalocele, monocardian, severe fatal achondroplasia and severe cleft lip and palate.

The included subjects were divided into two groups: The respiratory assistance group, which had a history of ventilator use during neonatal hospitalization, including invasive ventilator, non-invasive ventilator and high-frequency ventilation; and the no ventilator use group, of which patients had no history of ventilator use during hospitalization.

The indications for non-invasive ventilation were: i) Early prophylactic application in the delivery room for premature infants with spontaneous breathing (gestational age 25-28 weeks); ii) preterm infants at high risk of respiratory distress syndrome (RDS); iii) when the fraction of inspired oxygen $\left(\mathrm{FiO}_{2}\right)>0.3$, arterial oxygen saturations $\left(\mathrm{PaO}_{2}\right)<50$ $\mathrm{mmHg}(1 \mathrm{mmHg}=0.133 \mathrm{kpa})$ or transcutaneous oxygen saturations $\left(\mathrm{TcSO}_{2}\right)<90 \%$; iv) premature infant apnea; v) the condition of children with RDS was stable following pulmonary surfactant treatment, and the tracheal tube was removed; and vi) after conventional mechanical ventilation or high-frequency ventilation was removed, there were obvious tri-retraction signs and/or respiratory distress (20-22).

The indications of conventional mechanical ventilation (CMV) were as follows: i) Frequent apnea, with no effect after medication or CPAP intervention; ii) children with RDS who require PS treatment; iii) $\mathrm{FiO}_{2}>0.6-0.7$, $\mathrm{PaO}_{2}<50-60 \mathrm{mmHg}$ or $\mathrm{TcSO}_{2}<85 \%$ (except the cyanotic congenital heart disease); iv) $\mathrm{PaCO}_{2}>60-65 \mathrm{mmHg}$, accompanied by persistent acidosis ( $\mathrm{pH}<7.20)$; and $\mathrm{v}$ ) newborns under general anesthesia (22).
High-frequency ventilation is often used for the following situations (22-25): i) Pulmonary air leak syndromes, including pneumothorax, interstitial emphysema or bronchopleural fistula; ii) some congenital diseases, such as diaphragmatic hernia, pulmonary dysplasia and severe thoracic deformity; iii) persistent pulmonary hypertension, especially for those requiring inhalation of $\mathrm{NO}$; iv) lung diseases with severe non-uniform changes, such as meconium inhalation syndrome and severe pneumonia; and v) premature infant RDS, and can be used as the first choice after CMV failure.

The current study protocol followed the ethical guidelines of the Declaration of Helsinki (26) and was approved by the Ethics Committee of Changzhou Women and Children Health Care Hospital.

Patient information collection. Using the hospital's information system, a retrospective study was conducted to collect factors that may be associated with the use of ventilators in 3,578 patients. The data are anonymous, and the requirement for informed consent was therefore waived. Data included the general information and complication condition of mothers during the maternal pregnancy period, including the mothers' hospital number, age, polyembryony or not, gravidity and parity, the complications of pregnancy and delivery (such as anemia, hypertension, diabetes, infection, scarred uterus, cholestasis, hypoproteinemia, thrombocytopenia, uterine fibroid and hypothyroidism), whether the fetal position, placenta and umbilical cord were abnormal and whether the preterm birth was in vitro fertilization and embryo transfer. Furthermore, data regarding the condition of pediatric patients during the perinatal period was collected, and included the following: Whether there was premature rupture of membranes, the mode of delivery, the gestational age (weeks), 1-min and 5-min Apgar score (27), sex, birth weight and whether a ventilator was used. After removing unqualified cases, 3,394 subjects were included, of which $19.59 \%(665 / 3,394)$ required a ventilator (Fig. 1).

Statistical analysis. A total of 3,394 patients were included in the statistical analysis, 2,729 cases did not require ventilator use and 665 cases used a ventilator. Continuous variables were tested for normality using the Kolmogorov-Smirnov test. Data are presented as the mean \pm standard deviation or median (percentile 25 to percentile 75 ). When appropriate, continuous variables, including maternal age, birth weight and gestational age, were compared using unpaired Student's t-test or Mann-Whitney U test. Pregnancy times, 1-min and 5-min Apgar scores were compared using the Wilcoxon signed rank test. The remaining categorical variables were summarized using frequency and percentage and compared using $\chi^{2}$ test or Fisher's exact test. For all possible determinants of treatment with a ventilator or not, univariate logistic regression analysis was performed. All variables with a $\mathrm{P}<0.1$ (defined 'a priori') were considered relevant and included into the multivariate logistic regression analysis. Multivariate logistic regression analysis was used to define the factors that were independently associated with using a ventilator. Statistical analyses were performed with $\mathrm{R}$ version 3.4.1 (www.R-project.org). $\mathrm{P}<0.05$ was considered to indicate a statistically significant difference. 


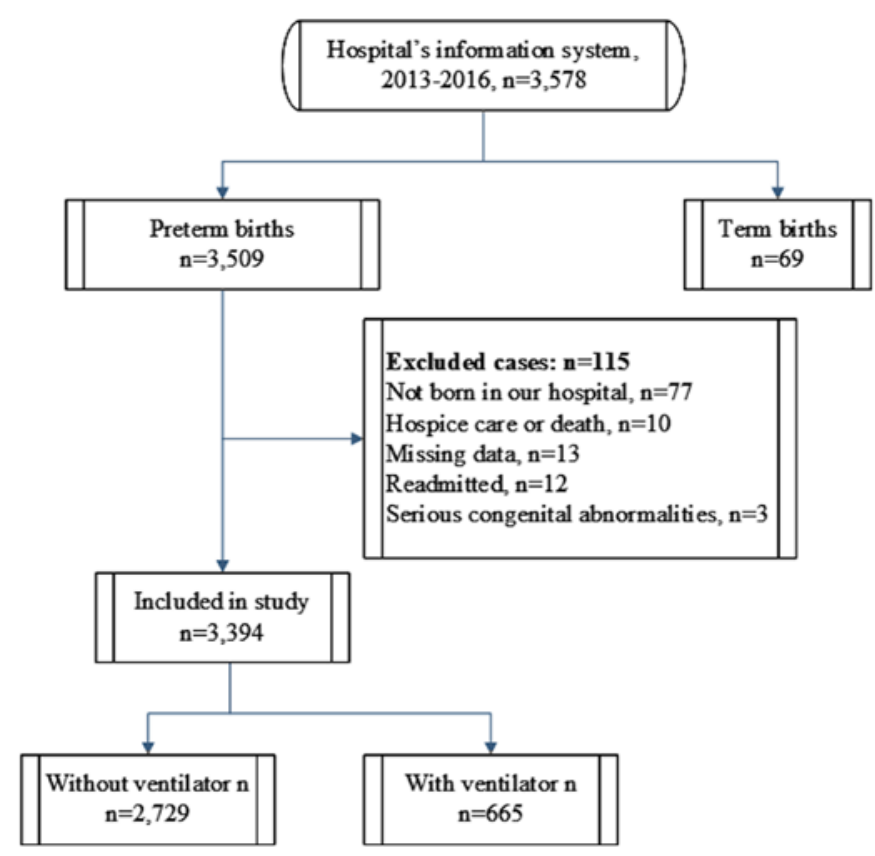

Figure 1. Flow chart outlining the protocol of the present study.

\section{Results}

Demographics and clinical characteristics. The results identified that among the factors during the maternal pregnancy period, there were significant differences between the two groups in terms of maternal anemia, abnormal fetal position, pregnancy with diabetes, placental abnormality, maternal infection, abnormality of umbilical cord, cholestasis during the maternal pregnancy period and neonates conceived by IVF (Table I). However, there were no statistically significant differences between the two groups in terms of maternal hypertension, scarred uterus, hypothyroidism and thrombocytopenia (Table I). Among the perinatal factors, the proportion of male infants who received ventilator rescue was significantly higher compared with the number of female infants. Furthermore, the patients who received ventilator rescue exhibited a lower 1-min and 5-min Apgar score, lower birth weight and smaller gestational age compared with those who did not receive ventilator treatment. There were significant differences between the groups in terms of whether the weight was suitable for gestational age (SGA/AGA/LGA), the mole of delivery (eutocia/caesarean section), pregnancy times, and premature rupture of membranes.

Risk factors associated with preterm infants who used ventilation. Univariate and multivariate logistic regression were used to analyze the risk factors for respiratory assistance in pediatric patients. The results demonstrated that placental abnormality, being male, cesarean section, low 1-min Apgar score, low birth weight and small gestational age were the independent risk factors for using respiratory assistance in rescue of premature infants (Table II).

Analysis of receiver operating characteristic (ROC) curve. The results from the multivariate regression analyses, which included birth weight, gestational age, 1-min Apgar, mode of

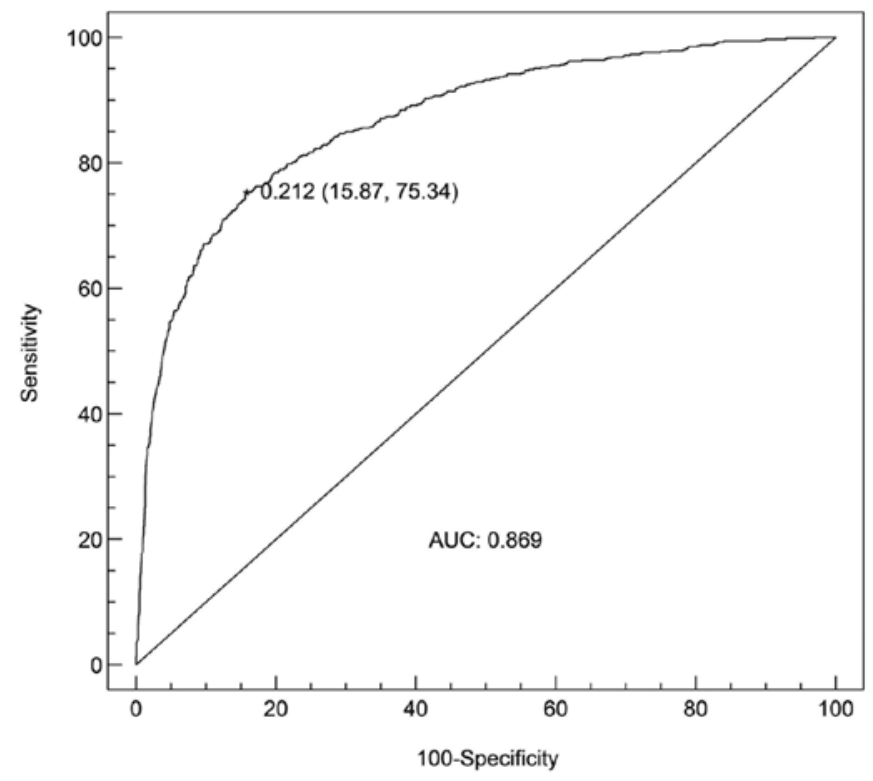

Figure 2. Received operator characteristic curve for the risk factors associated with respiratory assistance. AUC, area under the curve.

delivery (cesarean section/vaginal delivery), sex and placental abnormality, were used to construct the ROC curve analysis that predicted the use of infant ventilator in preterm infants. The area under the curve of the prediction model constructed in the present study was 0.869 and the cut-off value was 0.212 , which indicated that the prediction ability and discrimination of the model were generally effective (Fig. 2).

\section{Discussion}

Ventilator-assisted ventilation, which is an important treatment tool used in the Neonatal Intensive Care Unit (NICU), has developed rapidly and aided a number of premature infants (13). However, if respiratory assistance is delayed, the rescue outcomes for newborn patients whose conditions are continuously changing and difficult to predict may be unfavorable. The present study investigated the risk factors for the use of ventilation in advance, and whether it is possible to predict if preterm births will require ventilator support or not, which will determine whether the relevant equipment should be prepared and a pediatrician made available in order to rescue infants quickly and improve their chances of survival. In addition, the economic cost of treatment for premature infants is high, and with the improvement of medicine, more premature infants of decreased gestational ages survive, which increases this cost (28-30). Ventilator support involves a number of different pieces of equipment, medical workers and expenses, which can be reduced if the risk factors of ventilator support are managed effectively.

As an effective method to solve high-risk pregnancy, dystocia and other obstetric critical illness, the use of a cesarean section has been increasing each year, and in 2015, an estimated 29.7 million (21.1\%) births globally were by $\mathrm{CS}$, which represented almost a doubling in the proportion since 2000 , when 16.0 million $(12.1 \%)$ births were by CS (31). Although cesarean delivery can reduce the incidence of neonatal asphyxia and meconium inhalation, the risk of 
Table I. Demographics and clinical characteristics in premature babies with or without ventilator use.

A, Maternal pregnancy period

\begin{tabular}{|c|c|c|c|}
\hline Factor & $\begin{array}{c}\text { Without } \\
\text { ventilator, } \\
\mathrm{n}=2,729\end{array}$ & $\begin{array}{c}\text { With } \\
\text { ventilator, } \\
n=665\end{array}$ & P-value \\
\hline Anemia & & & $0.001^{\mathrm{b}}$ \\
\hline Yes & 1,234 & 347 & \\
\hline No & 1,495 & 318 & \\
\hline Hypertension & & & 0.118 \\
\hline Yes & 545 & 115 & \\
\hline No & 2,184 & 550 & \\
\hline Abnormal fetal position & & & $0.045^{\mathrm{a}}$ \\
\hline Yes & 441 & 129 & \\
\hline No & 2,288 & 536 & \\
\hline Diabetes & & & $0.018^{\mathrm{a}}$ \\
\hline Yes & 368 & 67 & \\
\hline No & 2,361 & 598 & \\
\hline Placental abnormality & & & $<0.001^{\mathrm{b}}$ \\
\hline Yes & 544 & 234 & \\
\hline No & 2,185 & 431 & \\
\hline Infection & & & $<0.001^{\mathrm{b}}$ \\
\hline Yes & 603 & 219 & \\
\hline No & 2,126 & 446 & \\
\hline $\begin{array}{l}\text { Abnormality of umbilical } \\
\text { cord }\end{array}$ & & & $0.004^{b}$ \\
\hline Yes & 423 & 74 & \\
\hline No & 2,306 & 591 & \\
\hline Scarred uterus & & & 0.243 \\
\hline Yes & 274 & 77 & \\
\hline No & 2,455 & 588 & \\
\hline Cholestasis & & & $0.004^{\mathrm{b}}$ \\
\hline Yes & 305 & 49 & \\
\hline No & 2,424 & 616 & \\
\hline Hypoproteinemia & & & 0.776 \\
\hline Yes & 269 & 68 & \\
\hline No & 2,460 & 597 & \\
\hline Conceived by IVF & & & $0.013^{\mathrm{a}}$ \\
\hline Yes & 364 & 65 & \\
\hline No & 2,365 & 600 & \\
\hline Thrombocytopenia & & & 0.405 \\
\hline Yes & 73 & 14 & \\
\hline No & 2,656 & 651 & \\
\hline Uterine fibroid & & & 0.786 \\
\hline Yes & 53 & 14 & \\
\hline No & 2,676 & 651 & \\
\hline Hypothyroidism & & & 0.573 \\
\hline Yes & 41 & 12 & \\
\hline No & 2,688 & 653 & \\
\hline Maternal age (years) ${ }^{c}$ & $28.18 \pm 4.94$ & $28.42 \pm 5.07$ & 0.266 \\
\hline
\end{tabular}

B, Perinatal period

\begin{tabular}{lccc}
\hline & $\begin{array}{c}\text { Without } \\
\text { ventilator, } \\
\mathrm{n}=2,729\end{array}$ & $\begin{array}{c}\text { With } \\
\text { ventilator, } \\
\mathrm{n}=665\end{array}$ & P-value \\
\hline Factor & $1.12 \pm 0.86$ & $1.10 \pm 0.77$ & 0.571 \\
Age (days) & & & $<0.001^{\mathrm{b}}$ \\
$\begin{array}{l}\text { Sex }, \text { female/male } \\
\text { Female }\end{array}$ & 1,231 & 250 & \\
Male & 1,498 & 415 &
\end{tabular}

Table I. Continued.

$\mathrm{B}$, Perinatal period

\begin{tabular}{|c|c|c|c|}
\hline Factor & $\begin{array}{c}\text { Without } \\
\text { ventilator, } \\
n=2,729\end{array}$ & $\begin{array}{c}\text { With } \\
\text { ventilator, } \\
n=665\end{array}$ & P-value \\
\hline AGA or not & & & $0.007^{\mathrm{b}}$ \\
\hline SGA & 321 & 72 & \\
\hline AGA & 2,328 & 587 & \\
\hline LGA & 81 & 6 & \\
\hline Mode of delivery & & & $<0.001^{\mathrm{b}}$ \\
\hline Eutocia & 1,142 & 329 & \\
\hline Cesarean & 1,587 & 336 & \\
\hline 1-min Apgar score ${ }^{\mathrm{d}}$ & $8(8-9)^{\mathrm{c}}$ & $7(6-8)$ & $<0.001^{\mathrm{b}}$ \\
\hline 5-min Apgar score & $8(8-9)^{c}$ & $8(7-8)$ & $<0.001^{\mathrm{b}}$ \\
\hline Monocyesis & & & $0.005^{\mathrm{b}}$ \\
\hline Yes & 1,949 & 511 & \\
\hline No & 780 & 154 & \\
\hline Pregnancy times & & & $0.010^{\mathrm{a}}$ \\
\hline 1 & 1,208 & 262 & \\
\hline 2 & 710 & 176 & \\
\hline 3 & 403 & 108 & \\
\hline$\geq 4$ & 408 & 119 & \\
\hline Parity & & & 0.767 \\
\hline Primiparous & 1,265 & 304 & \\
\hline Multiparous & 1,464 & 361 & \\
\hline Birth weight $(\mathrm{g})^{\mathrm{c}}$ & $2339.83 \pm 473.06$ & $1735.64 \pm 523.24$ & $<0.001^{\mathrm{b}}$ \\
\hline $\begin{array}{l}\text { Gestational age } \\
\text { (weeks) }^{\mathrm{c}}\end{array}$ & $34.29 \pm 1.62$ & $31.24 \pm 2.59$ & $<0.001^{\mathrm{b}}$ \\
\hline $\begin{array}{l}\text { Premature rupture of } \\
\text { membrane }\end{array}$ & & & $0.001^{\mathrm{b}}$ \\
\hline Yes & 1124 & 229 & \\
\hline No & 1605 & 436 & \\
\hline
\end{tabular}

${ }^{\mathrm{a}} \mathrm{P}<0.05 ;{ }^{\mathrm{b}} \mathrm{P}<0.01 ;{ }^{\mathrm{c}}$ values are presented as mean (standard deviation); ${ }^{\mathrm{d}}$ values are presented as median (range). SGA, small for gestational age; AGA, appropriate for gestational age; LGA, large for gestational age.

respiratory morbidity and the probability of admission into the NICU are significantly higher $(32,33)$. Furthermore, previous studies have reported that cesarean section is a risk factor for respiratory diseases, such as respiratory distress syndrome (34-36), transient shortness of breath (37) and pulmonary hypertension (38), but few of these studies examine the association between ventilator use and cesarean section. In the present study, cesarean section was demonstrated to be an independent risk factor for ventilator use.

Fetuses need to overcome the viscosity resistance, surface tension and tissue resistance of the lung fluid by accelerating their breathing rate after delivery, but fetuses delivered by cesarean section have significant restricted ventilatory dysfunction within $12 \mathrm{~h}$ of birth due to the lower tidal volume and minute ventilation volume compared with fetuses born via vaginal delivery (39). It has been previously suggested that the clearance of fetal lung fluid begins before birth, and neonates born via cesarean section without uterine contractions may have difficulty in removing fluid from their lungs, which can result in obstruction of ventilation (39). In addition, cesarean delivery makes infants more susceptible to 
Table II. Analysis of risk factors for using a ventilator in preterm infants.

A, Maternal pregnancy period

\begin{tabular}{|c|c|c|c|c|c|c|}
\hline \multirow[b]{2}{*}{ Variables } & \multicolumn{3}{|c|}{ Univariate regression analysis } & \multicolumn{3}{|c|}{ Multivariate regression analysis } \\
\hline & OR & $95 \% \mathrm{CI}$ & P-value & OR & $95 \% \mathrm{CI}$ & $\mathrm{P}$-value \\
\hline Anemia, yes/no & 1.322 & $1.116-1.566$ & $0.001^{\mathrm{b}}$ & 1.021 & $0.819-1.273$ & 0.854 \\
\hline Hypertension, yes/no & 0.838 & $0.671-1.046$ & 0.118 & & & \\
\hline Abnormal fetal position, yes/no & 1.249 & $1.005-1.552$ & $0.045^{\mathrm{a}}$ & 0.778 & $0.581-1.042$ & 0.092 \\
\hline Diabetes, yes/no & 0.719 & $0.546-0.947$ & $0.019^{\mathrm{a}}$ & 0.864 & $0.613-1.217$ & 0.402 \\
\hline Placental abnormality, yes/no & 2.181 & $1.813-2.623$ & $<0.001^{\mathrm{b}}$ & 1.284 & $1.002-1.646$ & $0.048^{\mathrm{a}}$ \\
\hline Infection, yes/no & 1.731 & $1.438-2.083$ & $<0.001^{\mathrm{b}}$ & 1.151 & $0.901-1.471$ & 0.259 \\
\hline Abnormality of umbilical cord, yes/no & 0.683 & $0.525-0.888$ & $0.004^{\mathrm{b}}$ & 0.832 & $0.605-1.145$ & 0.259 \\
\hline Scarred uterus, yes/no & 1.173 & $0.897-1.534$ & 0.243 & & & \\
\hline Cholestasis, yes/no & 0.632 & $0.462-0.866$ & $0.004^{\mathrm{b}}$ & 0.992 & $0.675-1.457$ & 0.967 \\
\hline Hypoproteinemia, yes/no & 1.042 & $0.787-1.379$ & 0.776 & & & \\
\hline Conceived by IVF, yes/no & 0.704 & $0.533-0.930$ & $0.014^{\mathrm{a}}$ & 0.789 & $0.528-1.181$ & 0.249 \\
\hline Thrombocytopenia, yes/no & 0.782 & $0.439-1.395$ & 0.406 & & & \\
\hline Uterine fibroid, yes/no & 1.086 & $0.599-1.969$ & 0.786 & & & \\
\hline Hypothyroidism, yes/no & 1.205 & $0.630-2.305$ & 0.574 & & & \\
\hline Maternal age (years) & 1.010 & $0.993-1.027$ & 0.258 & & & \\
\hline
\end{tabular}

B, Perinatal period

\begin{tabular}{|c|c|c|c|c|c|c|}
\hline \multirow[b]{2}{*}{ Variables } & \multicolumn{3}{|c|}{ Univariate regression analysis } & \multicolumn{3}{|c|}{ Multivariate regression analysis } \\
\hline & OR & $95 \% \mathrm{CI}$ & P-value & OR & $95 \% \mathrm{CI}$ & P-value \\
\hline Sex, female/male & 0.733 & $0.616-0.872$ & $<0.001^{\mathrm{b}}$ & 0.696 & $0.558-0.869$ & $0.001^{\mathrm{b}}$ \\
\hline Gestational age, SGA/AGA & 0.892 & $0.680-1.170$ & 0.41 & 0.887 & $0.579-1.356$ & 0.579 \\
\hline Gestational age, LGA/AGA & 0.294 & $0.128-0.667$ & $0.004^{\mathrm{b}}$ & 1.182 & $0.432-3.235$ & 0.745 \\
\hline $\begin{array}{l}\text { Delivery method: Cesarean } \\
\text { section/eutocia }\end{array}$ & 0.735 & $0.620-0.871$ & $<0.001^{\mathrm{b}}$ & 1.538 & $1.197-1.977$ & $<0.001^{\mathrm{b}}$ \\
\hline 1-min Apgar score & 0.479 & $0.443-0.518$ & $<0.001^{\mathrm{b}}$ & 0.727 & $0.638-0.828$ & $<0.001^{\mathrm{b}}$ \\
\hline 5-min Apgar score & 0.300 & $0.261-0.343$ & $<0.001^{\mathrm{b}}$ & 0.908 & $0.740-1.114$ & 0.356 \\
\hline Polyembryony, yes/no & 0.753 & $0.618-0.918$ & $0.005^{\mathrm{b}}$ & 0.763 & $0.571-1.018$ & 0.066 \\
\hline Pregnancy times & 1.105 & $1.024-1.192$ & $0.01^{\mathrm{a}}$ & 1.005 & $0.911-1.109$ & 0.916 \\
\hline Parity, $\geq 2 / 1$ & 1.026 & $0.866-1.216$ & 0.767 & & & \\
\hline Birth weight (g) & 0.997 & $0.997-0.998$ & $<0.001^{\mathrm{b}}$ & 0.999 & $0.999-1.000$ & $0.005^{\mathrm{b}}$ \\
\hline Gestational age (weeks) & 0.519 & $0.493-0.546$ & $<0.001^{\mathrm{b}}$ & 0.616 & $0.560-0.678$ & $<0.001^{\mathrm{b}}$ \\
\hline Premature rupture of membrane, yes/no & 0.750 & $0.628-0.895$ & $0.001^{\mathrm{b}}$ & 0.966 & $0.769-1.214$ & 0.769 \\
\hline
\end{tabular}

${ }^{\mathrm{a}} \mathrm{P}<0.05 ;{ }^{\mathrm{b}} \mathrm{P}<0.01$. OR, odds ration; CI, confidence interval; SGA, small for gestational age; AGA, appropriate for gestational age; LGA, large for gestational age.

NRDS and its accompanying increase in endothelin-1 levels, which may indirectly result in the occurrence of Persistent Pulmonary Hypertension of Newborn (38). Exposure of newborns delivered via caesarean section with the combined effect of these pathophysiological events may result in the occurrence of respiratory distress, hypoxia, acidosis and transition-delay (34). Therefore, the risk of respiratory diseases in premature infants delivered by cesarean section is higher, which suggests that the indications for elective cesarean section should be strictly controlled when selecting this method of delivery for premature infants in clinical practice, thus reducing their risk of ventilator use.

A previous study which measured the association between fetal sex and preterm birth in four original datasets found that premature birth is more common in males, with $\sim 55 \%$ of premature births occurring in male infants (40). In addition, male infants exhibit a higher mortality rate compared with female infants born in the same gestation period (41). The results of the present study suggested that the male sex is an independent risk factor for ventilator use, which is consistent 
with previous studies reporting that the incidence of certain respiratory-related diseases in male newborns is significantly higher compared with that of female infants. For example, the incidence of NRDS in late-stage premature infants with different sexes is statistically different (male infants have a higher incidence compared with female infants) $(42,43)$. Another study compared 130 premature male infants with 106 premature female infants and revealed that $60.8 \%$ of male infants required machinery ventilation support compared with only $46.2 \%$ of female infants, and the incidence of Chronic Lung Disease in male infants was higher compared with that of female infants (44). A previous study reported that after birth, male infants express less transforming growth factor (TGF)- $\beta$ compared with female infants, and low levels of TGF- $\beta$ are important indicators for predicting aerobic therapy, and at 36 weeks, male infants require a higher oxygen supply compared with female infants, which may cause premature male infants to lack oxygen, thus deepening and accelerating the breathing and aggravating damage to the respiratory system (45). Another previous study indicated that the carbon dioxide partial pressure of male infants is lower compared with female infants within $24 \mathrm{~h}$ after birth (46), while the low level of carbon dioxide partial pressure is associated with a low level of pulmonary surfactant, which may account for the sex difference in respiratory diseases. In addition, genetic factors may be responsible for sex differences. For example, a previous study revealed that allele 186 Asn and haploid 138 Asn-186 Asn are independent risk factors for RDS (47), and the association between allele 186 Asn and RDS was observed among male infants (48).

In the present study, it was revealed that placental abnormalities, such as placental abruption, placenta previa, placental adhesions and abnormal invasion placenta (AIP), may also increase the risk of ventilator use. Ahn et al (49) studied newborns born by 2,067 mothers with placenta previa and demonstrated that newborns whose anterior placenta previa in the second and third trimesters was correlated with NRDS. Furthermore, a previous study reported that AIP increased the risk of NRDS, and AIP cases required longer respiratory assistance compared with the control group, which was consistent with the results of the current study (50).

Apgar score includes heart rate, respiratory effort, muscle tone, reflex irritability and color, which is the standard evaluation method of checking the health condition of the infant immediately after birth (27). This score has been used as a predictive index for neonatal mortality and morbidity, and for later neurologic or developmental disability (51). Numerous factors can influence Apgar score, such as maternal education and BMI, gestational age, pathological obstetrics, longer duration of the second stage of labor, neonatal weight and meconium-stained amniotic fluid (52). The present results suggested that 1-min Apgar score was a risk factor for respiratory assistance in premature infants, indicating that weight control in pregnant women, reduction of the preterm birth and other measures may reduce the use of ventilators.

As aforementioned, lung-related structures and metabolites mature in the last trimester, and thus premature infants often require respiratory assistance $(6,7,53)$. In the current study, the ventilator utilization rates of gestational age $<28$ weeks, 28-31 weeks and 32-36 weeks were 89.58\% (43/48),
$65.38 \%(321 / 491)$ and $10.54 \%(301 / 2,855)$, respectively (data not shown); therefore, it was suggested that the younger the gestational age, the more ventilator support is required. Birth weight is also a risk factor for numerous respiratory diseases $(54,55)$. To avoid these diseases, the pregnancy period should be extended as soon as possible, as well as ensuring good nutrition, and timely and regular antenatal visits during pregnancy. However, multiple sociodemographic, nutritional, biological and environmental factors can increase the risk of preterm birth and low birth weight $(56,57)$. Therefore, methods for appropriate interventions to reduce the incidence of premature infants and low birth weight remain challenging.

With the increasing incidence of premature infants, how to reduce the use of ventilators, and use the ventilators correctly and timely is of great concern (1). However, there is limited research on the risk factors of ventilator use in premature infants worldwide, and there are few predictive models constructed for its use. The high-risk factors associated with respiratory assistance observed in the present study, including placental abnormality, being male, cesarean section, low 1-min Apgar score, low birth weight and small gestational age, may reduce the use of respiratory assistance by developing strategies to decrease these factors, and to clinically guide medical staff to identify pediatric patients with high risk factors, which will allow advanced preparation of the ventilator and ensure the availability of a pediatrician. Collectively, these actions could help to minimize the time of hypoxia within newborns, which will increase their survival.

There are some limitations of the present study that require discussion. Firstly, the current study used data from a single-center that has not been validated in other hospitals. Secondly, there was no in-depth discussion of the individual risk factors, such as a stratified analysis based on gestational age, which would provide more accurate risk factor analysis for the respiratory assistance of premature infants in different gestational age groups. This should be performed in future studies in order to provide a basis for preparing for the respiratory assistance of premature infants.

In conclusion, the present results suggested that cesarean section, male neonates, placental abnormality, low 1-min Apgar score, low birth weight and lower gestational age represented independent risk factors for the use of ventilators in premature infants. Thus, increased effort to reduce the use of ventilators and provide early detection of those requiring assistance should be performed for premature infants who require respiratory assistance to improve their survival rate and quality of life. Firstly, the indications for elective cesarean section should be strictly controlled when selecting cesarean section for premature infants in clinical practice. Secondly, ensuring nutrition and the timely and regular antenatal visits during pregnancy are important, as well as the pregnancy period should be extended as soon as possible Finally, for premature infants who have risk factors for using the ventilator, ventilator support such as the relevant equipment and personnel should be prepared in time to improve their chances of survival.

\section{Acknowledgements}

Not applicable. 


\section{Funding}

No funding was received.

\section{Availability of data and materials}

The datasets used and/or analyzed during the current study are available from the corresponding author on reasonable request.

\section{Authors' contributions}

HXL, ZLM and HYW were study investigators and participated in study design, patient recruitment, acquisition of data, and/or analysis and interpretation of the findings. HXL, ZLM, HYW, CJG and SC contributed to data analysis, drafting and revising the article, gave final approval of the version to be published, and agree to be accountable for all aspects of the work. All authors read and approved the final version of the manuscript.

\section{Ethics approval and consent to participate}

The present study protocol followed the ethical guidelines of the Helsinki Declaration revised in 2008 and was approved by the Ethics Committee of Changzhou Women and Children Health Care Hospital (Changzhou, China).

\section{Patient consent for publication}

Not applicable.

\section{Competing interests}

The authors declare that they have no competing interests.

\section{References}

1. Chawanpaiboon S, Vogel JP,Moller AB,Lumbiganon P,PetzoldM Hogan D, Landoulsi S, Jampathong N, Kongwattanakul K, Laopaiboon $\mathrm{M}$, et al: Global, regional, and national estimates of levels of preterm birth in 2014: A systematic review and modelling analysis. Lancet Glob Health 7: e37-e46. 2019.

2. Ancel PY, Goffinet F, Kuhn P, Langer B, Matis J, Hernandorena X, Chabanier P, Joly-Pedespan L, Lecomte B, Vendittelli F, et al; EPIPAGE-2 Writing Group: Survival and morbidity of preterm children born at 22 through 34 weeks' gestation in France in 2011: Results of the EPIPAGE-2 cohort study. JAMA Pediatr 169: 230-238, 2015.

3. Kiechl-Kohlendorfer U, Simma B, Urlesberger B, Maurer-Fellbaum U, Wald M, Wald M, Weissensteiner M, Ehringer-Schetitska D, Berger A, Kurz H, et al; Austrian Preterm Outcome Study Group: Low mortality and short-term morbidity in very preterm infants in Austria 2011-2016. Acta Paediatr 108: 1419-1426, 2019.

4. Fellman V, Hellström-Westas L, Norman M, Westgren M, Källén K, Lagercrantz H, Marsál K, Serenius F and Wennergren M; EXPRESS Group: One-year survival of extremely preterm infants after active perinatal care in Sweden. JAMA 301: 2225-2233, 2009

5. Platt MJ: Outcomes in preterm infants. Public Health 128: 399-403, 2014

6. Alphonse RS, Rajabali S and Thébaud B: Lung injury in preterm neonates: The role and therapeutic potential of stem cells Antioxid Redox Signal 17: 1013-1040, 2012.

7. Vento M, Aguar M, Escobar J, Arduini A, Escrig R, Brugada M, Izquierdo I, Asensi MA, Sastre J, Saenz P, et al: Antenatal steroids and antioxidant enzyme activity in preterm infants: Influence of gender and timing. Antioxid Redox Signal 11: 2945-2955, 2009.
8. Cools F, Offringa M and Askie LM: Elective high frequency oscillatory ventilation versus conventional ventilation for acute pulmonary dysfunction in preterm infants Cochrane Database Syst Rev: Mar 19, 2015 (Epub ahead of print). doi: 10.1002/14651858. CD000104.pub4.

9. Hillman NH, Kallapur SG and Jobe AH: Physiology of transition from intrauterine to extrauterine life. Clin Perinatol 39: 769-783, 2012.

10. Owen LS, Manley BJ, Davis PG and Doyle LW: The evolution of modern respiratory care for preterm infants. Lancet 389: 1649-1659, 2017.

11. Spotswood N, Orsini F, Dargaville P, Marshall P, Schmidt P, Craven P, de Waal K, Simmer K, Gill A, Pillow J, et al; Australian and New Zealand Neonatal Network: Association of center-specific patient volumes and early respiratory management practices with death and bronchopulmonary dysplasia in preterm infants. J Pediatr 210: 63-68.e2, 2019.

12. Yang X, Xu PF, Shan L, Lang LG, Du L and Jia FY: Advances in respiratory assessment and treatment in children undergoing invasive mechanical ventilation. Zhongguo Dang Dai Er Ke Za Zhi 21: 94-99, 2019 (In Chinese).

13. Vento $M$ and Lista G: Managing preterm infants in the first minutes of life. Paediatr Respir Rev 16: 151-156, 2015.

14. Dunn MS, Kaempf J, de Klerk A, de Klerk R, Reilly M, Howard D, Ferrelli K, O'Conor J and Soll RF; Vermont Oxford Network DRM Study Group: Randomized trial comparing 3 approaches to the initial respiratory management of preterm neonates. Pediatrics 128: e1069-e1076, 2011.

15. Tooley J and Dyke M: Randomized study of nasal continuous positive airway pressure in the preterm infant with respiratory distress syndrome. Acta Paediatr 92: 1170-1174, 2003.

16. Pfister RH and Soll RF: Initial respiratory support of preterm infants: The role of CPAP, the INSURE method, and noninvasive ventilation. Clin Perinatol 39: 459-481, 2012.

17. Rivera R and Tibballs J: Complications of endotracheal intubation and mechanical ventilation in infants and children. Crit Care Med 20: 193-199, 1992.

18. Iosifidis E, Pitsava G and Roilides E: Ventilator-associated pneumonia in neonates and children: A systematic analysis of diagnostic methods and prevention. Future Microbiol 13: 1431-1446, 2018.

19. Mao JB, Yu XT, Shen LJ, Wu MY, Lyu Z, Lao JM, Li HX, Wu HF and Chen YQ: Risk factors of retinopathy of prematurity in extremely low birth weight infants by strictly controlling oxygen inhalation after birth. Zhonghua Yan Ke Za Zhi 55: 280-288, 2019 (In Chinese).

20. Sweet DG, Carnielli V, Greisen G, Hallman M, Ozek E, Plavka R, Saugstad OD, Simeoni U, Speer CP, Vento M, et al; European Association of Perinatal Medicine: European consensus guidelines on the management of neonatal respiratory distress syndrome in preterm infants - 2013 update. Neonatology 103: 353-368, 2013.

21. Committee on Fetus and NewbornAmerican Academy of Pediatrics: Respiratory support in preterm infants at birth. Pediatrics 133: 171-174, 2014.

22. Cloherty JP, Eichenwald EC, Hansen AR and Stark AR (eds): Manual of Neonatal Care. 7th edition. Lippincott Williams and Wilkins, London, 2012.

23. Rimensberger PC (ed): Pediatric and Neonatal Mechanical Ventilation. Springer, New York, NY, 2015.

24. Donn SM and Sinha SK (eds): Manual of Neonatal Respiratory Care. 3rd edition. Springer, New York, NY, 2012.

25. Goldsmith JP, Karotkin EH and Siede BL : Assisted Ventilation of the Neonate. 5th edition. Elsevier, Louis, 2011.

26. World Medical Association: World Medical Association Declaration of Helsinki: Ethical principles for medical research involving human subjects. JAMA 310: 2191-2194, 2013.

27. Apgar V: A proposal for a new method of evaluation of the newborn infant. Curr Res Anest Anal 32: 260-267, 1953.

28. Rocha G, Soares P, Gonçalves A, Silva AI, Almeida D, Figueiredo S, Pissarra S, Costa S, Soares H, Flôr-de-Lima F, et al Respiratory care for the ventilated neonate. Can Respir J: Aug 13, 2018 (Epub ahead of print). doi: 10.1155/2018/7472964.

29. Lancet T; The Lancet: The global burden of preterm birth. Lancet 374: 1214-1214, 2009.

30. Donda K, Vijayakanthi N, Dapaah-Siakwan F, Bhatt P, Rastogi D and Rastogi S: Trends in epidemiology and outcomes of respiratory distress syndrome in the United States. Pediatr Pulmonol 54: 405-414, 2019. 
31. Boerma T, Ronsmans C, Melesse DY, Barros AJ, Barros FC, Juan L, Moller AB, Say L, Hosseinpoor AR, Yi M, et al: Global epidemiology of use of and disparities in caesarean sections. Lancet 392: 1341-1348, 2018

32. Ahimbisibwe A, Coughlin K and Eastabrook G: Respiratory morbidity in late preterm and term babies born by elective Caesarean sectio. J Obstet Gynaecol Can 41: 1144-1149, 2019 (Epub ahead of print). doi: org/10.1016/j.jogc.2018.11.002.

33. Kamath BD, Todd JK, Glazner JE, Lezotte D and Lynch AM: Neonatal outcomes after elective cesarean delivery. Obstet Gynecol 113: 1231-1238, 2009.

34. Altman M, Vanpée M, Cnattingius S and Norman M: Risk factors for acute respiratory morbidity in moderately preterm infants. Paediatr Perinat Epidemiol 27: 172-181, 2013.

35. Gerten KA, Coonrod DV, Bay RC and Chambliss LR: Cesarean delivery and respiratory distress syndrome: Does labor make a difference? Am J Obstet Gynecol 193: 1061-1064, 2005.

36. Berthelot-Ricou A, Lacroze V, Courbiere B, Guidicelli B, Gamerre $\mathrm{M}$ and Simeoni U: Respiratory distress syndrome after elective caesarean section in near term infants: A 5-year cohort study. J Matern Fetal Neonatal Med 26: 176-182, 2013.

37. Rijal $P$ and Shrestha M: Scenario of neonatal respiratory distress in Tertiary Hospital. J Nepal Health Res Counc 16: 131-135, 2018.

38. Babooa N, Shi WJ and Chen C: Factors relating caesarean section to persistent pulmonary hypertension of the newborn. World J Pediatr 13: 517-527, 2017.

39. Dileep A, Khan NB and Sheikh SS: Comparing neonatal respiratory morbidity in neonates delivered at term by elective Caesarean section with and without dexamethasone: Retrospective cohort study. J Pak Med Assoc 65: 607-611, 2015.

40. Zeitlin J, Saurel-Cubizolles MJ, De Mouzon J, Rivera L, Ancel PY, Blondel B and Kaminski M: Fetal sex and preterm birth: are males at greater risk? Hum Reprod 17: 2762-2768, 2002.

41. Kent AL, Wright IM and Abdel-Latif ME; New South Wales and Australian Capital Territory Neonatal Intensive Care Units Audit Group: Mortality and adverse neurologic outcomes are greater in preterm male infants. Pediatrics 129: 124-131, 2012.

42. Anadkat JS, Kuzniewicz MW, Chaudhari BP, Cole FS and Hamvas A: Increased risk for respiratory distress among white, male, late preterm and term infants. J Perinatol 32: 780-785, 2012.

43. Ye W, Zhang T, Shu Y, Fang C, Xie L, Peng K and Liu C: The influence factors of neonatal respiratory distress syndrome in Southern China: A case-control study. J Matern Fetal Neonatal Med 33: 1678-1682, 2020.

44. Elsmén E, Hansen Pupp I and Hellström-Westas L: Preterm male infants need more initial respiratory and circulatory support than female infants. Acta Paediatr 93: 529-533, 2004.

45. Lecart C, Cayabyab R, Buckley S, Morrison J, Kwong KY, Warburton D, Ramanathan R, Jones CA and Minoo P: Bioactive transforming growth factor-beta in the lungs of extremely low birthweight neonates predicts the need for home oxygen supplementation. Biol Neonate 77: 217-223, 2000.
46. Dammann O, Allred EN, Kuban KC, van Marter LJ, Stewart JE, Pagano $\mathrm{M}$ and Leviton A; Development Epidemiology Network Investigators: Hypocarbia during the first 24 postnatal hours and white matter echolucencies in newborns $<$ or $=28$ weeks gestation. Pediatr Res 49: 388-393, 2001.

47. Fatahi N, Dalili H, Kalani M, Niknafs N, Shariat M, Tavakkoly-Bazzaz J, Amini E, Esmaeilnia Shirvani T, Hardani AK, Taheritafti R, et al: Association of SP-C gene codon 186 polymorphism (rs1124) and risk of RDS. J Matern Fetal Neonatal Med 30: 2585-2589, 2017.

48. Lahti M, Marttila R and Hallman M: Surfactant protein C gene variation in the Finnish population - association with perinatal respiratory disease. Eur J Hum Genet 12: 312-320, 2004.

49. Ahn KH, Lee EH, Cho GJ, Hong SC, Oh MJ and Kim HJ: Anterior placenta previa in the mid-trimester of pregnancy as a risk factor for neonatal respiratory distress syndrome. PLoS One 13: e0207061, 2018.

50. Spillane NT, Zamudio S, Alvarez-Perez J, Andrews T, Nyirenda T, Alvarez M and Al-Khan A: Increased incidence of respiratory distress syndrome in neonates of mothers with abnormally invasive placentation. PLoS One 13: e0201266, 2018.

51. Hegyi T, Carbone T, Anwar M, Ostfeld B, Hiatt M, Koons A, Pinto-Martin J and Paneth N: The apgar score and its components in the preterm infant. Pediatrics 101: 77-81, 1998

52. Yang C, Chen X, Zu S and He F: Retrospective analysis of risk factors for low 1-minute Apgar scores in term neonates. Braz J Med Biol Res 52: e9093, 2019.

53. Dargaville PA and Tingay DG: Lung protective ventilation in extremely preterm infants. J Paediatr Child Health 48: 740-746, 2012.

54. Jiangsu Multicenter Study Collaborative Group for Breastmilk Feeding in Neonatal Intensive Care Units: [Clinical characteristics and risk factors of very low birth weight and extremely low birth weight infants with bronchopulmonary dysplasia: Multicenter retrospective analysis]. Zhonghua Er Ke Za Zhi 57: 33-39, 2019

55. Undela K,Mohammed BTS,Gurumurthy P. Impact of preterm birth and low birth weight on medical conditions, medication use and mortality among neonates: a prospective observational cohort studyWorld journal of pediatrics : WJP,2019,():.https://doi. org/10.1007/s12519-019-00239-1..

56. Goldenberg RL, Culhane JF, Iams JD and Romero R: Epidemiology and causes of preterm birth. Lancet 371: 75-84, 2008.

57. Negandhi PH, Negandhi HN, Zodpey SP, Ughade SN and Biranjan JR: Risk factors for low birth weight in an Indian urban setting: A nested case control study. Asia Pac J Public Health 26: 461-469, 2014.

(i) $\ominus$ This work is licensed under a Creative Commons Attribution-NonCommercial-NoDerivatives 4.0 International (CC BY-NC-ND 4.0) License. 